\title{
Nutrient Foramina of The Human Patellar Bone. A Novel Macroscopic Morphology Classification
}

\author{
Gregory Tsoucalas*1, Eleni Panagouli ${ }^{1}$, Christos P Zafeiris ${ }^{2}$, Vasilios Raoulis ${ }^{3}$, Vasilios Thomaidis ${ }^{1}$, \\ Aristeidis $\mathrm{H} \mathrm{Zibis}^{3}$ and Aliki Fiska ${ }^{1}$ \\ ${ }^{1}$ Department of Anatomy, School of Medicine, Democritus University of Thrace, Alexandroupolis, Greece \\ ${ }^{2}$ Laboratory for Research of Musculoskeletal System (LRMS) 'T. Garofalidis", KAT Hospital, Athens, Greece \\ ${ }^{3}$ Department of Anatomy, Faculty of Medicine, University of Thessaly, Larissa, Greece
}

*Corresponding author: Gregory Tsoucalas, Department of Anatomy, School of Medicine, Ierolohiton 155, Agioi Anargyroi, Volos, Greece

\begin{abstract}
ARTICLE INFO
Received: 慧 April 26, 2019

Published: 蔧 May 06, 2019

Citation: Gregory Tsoucalas, Eleni Panagouli, Christos P Zafeiris, Vasilios Raoulis, Vasilios Thomaidis, Aristeidis H Zibis, Aliki Fiska. Nutrient Foramina of The Human Patellar Bone. A Novel Macroscopic Morphology Classification. Biomed J Sci \& Tech Res 17(5)-2019. BJSTR. MS.ID.003051.
\end{abstract}

Keywords: Patellar blood supply; Nutrient arteries; Clinical anatomy
ABSTRACT

Introduction: Patella is the largest sesamoid bone of the human body. Despite having an important role in the knee joint movement, it is rather neglected concerning its study. Numerous studies exist for its classification using the posterior articular surface, while for the anterior which is pierced by a series of nutrient foramina (NF) none exists.

Methods and Materials: The local Municipal authorities of Volos city gave the permission for the conduction of our study. After a thorough research of 201 skeletons 104 patellas entered our study. A macroscopic cartography be three independent researchers was performed. A statistical analysis followed with the aim to design a patellar cartography in the anterior surface and to classify the bone according to NFs.

Results: Our study indicated a mean of 12.564 and $12.383 \mathrm{NF}$ for the right and left patella bones respectively Only the bones of the female skeletons present a significant difference of the mean number of NF between the upper and lower areas. Various results indicated a significant difference in their distribution in the case when patella is divided into quartiles or into 20 different regions of interest. Moreover 8 different patellar types emerged to describe a new classification of the bone.

Conclusion: Blood supply of the patella bone plays a role in their fracture and refracture, with the avascular necrosis to be the most important side effect after a knee lesion or surgical procedure. Their number and position in the anterior surface needs further investigation for complications during the daily clinical practice to be avoided.

\section{Introduction}

Patella is the largest sesamoid bone of the human body, contained within the tendon of the quadriceps femoral muscle in front of the knee. The distance from the lower pole to the insertion of the tendon at the tibial tuberosity is about equal to the midsagital height of the patella. The prepatellar bursa separates the bone from the skin. The patellofemoral joint is a part of the knee joint. The normal anatomical position of the patellar bone is rather difficult to be determined, as the position of the tibial tuberosity may vary [1-3]. Blackburne and Peel in 1977 compared the height of the patella from the tibial plateau to its articular length, demonstrating a ratio of 0.8 to refer to normal position, indicating any deviation as a clinical problem [4].

The majority of the patellar bones, about $60 \%$, are depicted as roughly triangular in shape, concerning the outline of the bone. However, oblique, elliptical and circular shapes may be found too [5]. The base is placed superiorly and the apex inferiorly, the later lying just proximal to the line of the knee joint in the anatomical position. It is compressed antero-posteriorly and has two surfaces, an anterior and a posterior-articular one and three borders (superior, medial and lateral). The posterior surface, covered 
with hyaline cartilage, is separated into 3 facets, the medial, the lateral and the odd facet. The anterior surface is covered by the aponeurosis of the quadriceps tendon and bears 10-12 nutrient foramina lying between longitudinal fissures, markings made by the quadriceps tendon.

Experimental cadaveric studies demonstrated that the patellar bone improves the biomechanical efficiency of knee extension, especially towards the end of its range. It has the ability to hold the patellar tendon away from the axis of the movement, thus increasing the pull of the quatriceps muscle. In general, the patella has a protective role for the anterior aspect of the knee joint; it serves as the insertion for the quadriceps tendon and finally functions as a fulcrum to maximize the efficiency of the extensor mechanism [6]. The patellar bone receives centripetal blood supply from the genicular arteries. The superior vessels are lying anterior to the quadriceps tendon and the inferior vessels are passing posterior to the patellar ligament [7], while further studies demonstrated that the most significant blood supply to the bone penetrates the inferior pole along the infrapatellar fat pad.

The patella is a bone which experiences complex, dynamic loading patterns and may be fractured due to the infliction of direct or indirect forces. The mechanism of injury indicates the fracture pattern. A series of non-operative and surgical methods are available for the fracture management. Complications are rare and the bone fragments' union rates, based on the Bostman grading scale, are high, after surgical fixation. Non-union cases and infection are rare complications, more likely to happen in open fractures [8-9]. Moreover, osteonecrosis of the patella is reported as high as $25 \%$, though presenting no important clinical outcomes $[7,10]$. A compromise of the blood supply itself not only prevents bone healing but it constitutes an additional factor for a novel fracture. Hence, this research endeavors to cartograph the nutrient foramina (NF) of the anterior surface of the patellar bone, and create a classification index which may be helpful, in patellar fractures and patelloplasty.

\section{Method and Materials}

A total number of 201 skeletons of the Municipal Cemetery of Volos were studied and a series of 135 patellas were collected and analyzed. Due to the fact that not all skeletons were preserved in total, we have included in the study only the first patella discovered form each skeleton with a random selection. The mean standard deviation of the age of the examined sample was $81.1 \pm 8.5$ years (geriatric population, range: 59-101 yrs). Patella bones presenting signs of fracture, arthritis, osteoporosis and bone tissue damage due to burial conditions or time lesions were excluded. A number of 104 dry bone patellas entered the study (right sided $n=48$, left sided $n=56$, male $n=55$, female $=49$ ). The study was conducted under the written license of the Municipal authorities of Volos in a time interval between May of 2018 and March of 2019.

Two independent researchers designed the regions of interest on the patellas and cartographed the distribution of their NF. In the case of disagreement in number and area of distribution, a third independent researcher had been taking the final decision. All researchers were qualified for anatomical studies. A statistical analysis was conducted, presenting a cluster of results concerning NF mean number and distribution, while a morphological categorization of the patellar bones was performed based on the NFs discovered in their anterior surface.

\section{Statistical Analysis}

Comparisons of the mean number of the NF between right and left sided, as well as male vs female patellar bones were performed using non-parametric Mann-Whitney test. Analysis of variance (ANOVA) for repeated measures was used to assess the variation of NF count among different quartiles-areas of interest. Multiple paired comparisons were performed using the Bonferroni correction. Wilcoxon test was also performed to compare NF count between upper vs. lower areas and left vs. right areas. Statistical significance was accepted for $p$-values $<0.05$, while all tests were two-tailed. Statistical analysis was performed by SPSS (IBM Corp. Released 2017. IBM SPSS Statistics for Windows, Version 25.0. Armonk, NY: IBM Corp.).

\section{Results}

Nutrient foramina (NF) in the anterior surface of the patella bone are described in numbers above ten per bone. Our study indicates a mean of 12.564 and $12.383 \mathrm{NF}$ for the right and left patella bones respectively (Table 1) with no significant difference ( $p=0.767)$ among them. The patella may be divided with the horizontal medial line connecting its two margins (upper and lower part) and the vertical medial line which connects the apex and the center of the bone's base (right and left part) into 4 quartiles (A to D regions of interest - ROIs, Figure 1). By comparing the mean number of NF in upper to lower part for the total sample, no significant difference was observed in upper (A+B ROIs) vs lower area $(\mathrm{C}+\mathrm{D}$ ROIs- $\mathrm{p}=0.401)$ and right $(\mathrm{B}+\mathrm{C}$ ROIs) vs left area $(\mathrm{A}+\mathrm{D}$ ROIs$\mathrm{p}=0.180$ ). The same stands for the males' subgroup [upper vs. lower area $\mathrm{p}=0.345$ and right vs. left area $\mathrm{p}=0.546]$. For the females' subgroup the results were $\mathrm{p}=0.069$ for upper vs. lower area and $\mathrm{p}=0.276$ for right vs. left area. Thus, only the bones of the female skeletons present a significant difference of the mean number of NF between the upper and lower areas. More details may be seen in Table 2. Therefore, a significant difference of the mean number of $\mathrm{NF}$ is indicated for the upper $(\mathrm{p}<0.001)$ and left $(\mathrm{p}=0.01)$ areas between male and female subgroups (Table 2). 
Table 1: Right vs Left sided patella's and the mean total of the NFs

\begin{tabular}{|c|c|c|c|c|c|}
\hline & Side & Number & Mean & Std. Deviation & p-value \\
\hline \multirow{2}{*}{ Total NF } & Right side & 48 & 12,56 & 4,021 & 3,788 \\
\cline { 2 - 6 } & Left side & 56 & 12,38 & 0.767 \\
\hline
\end{tabular}

Table 2: Differences of NF between different areas of interest (upper-lower and right-left) for the total sample and for males and females separately

\begin{tabular}{|c|c|c|c|c|}
\hline Patella area & Total sample & Males & Females & p-value \\
\hline Upper area & $6.17 \pm 3.45$ & $7.07 \pm 2.72$ & $5.16 \pm 3.91$ & $<0.001$ \\
\hline Lower area & $6.29 \pm 2.68$ & $6.35 \pm 3.06$ & $6.22 \pm 2.24$ & 0.768 \\
\hline Right area & $6.50 \pm 2.99$ & $6.87 \pm 2.67$ & $6.08 \pm 3.28$ & 0.232 \\
\hline Left area & $5.96 \pm 2.45$ & $6.55 \pm 2.43$ & $5.31 \pm 2.33$ & 0.010 \\
\hline
\end{tabular}

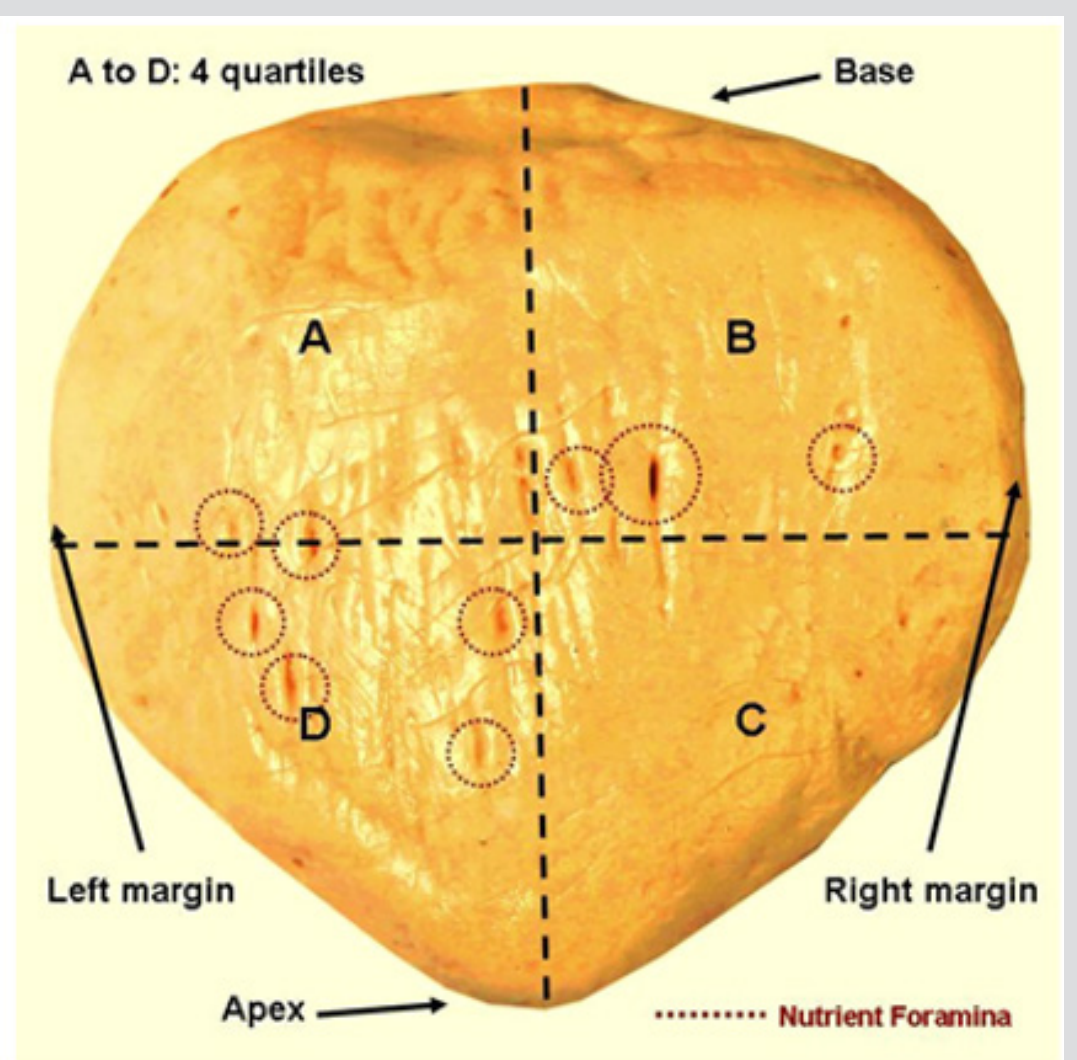

Figure 1: Patellar bone divided into 4 quartiles (A to D ROIs).

By comparing the mean number of NF in the A to D ROIs of the bone for the total sample $(n=104)$, it was observed that there is a significant difference $(\mathrm{p}=0.002)$ of the mean number of NF among the 4 ROIs (quartiles) (Table 3) (Figure 2). Meanwhile, there is a significant difference of the mean number of NF among the $\mathrm{B}$ and $\mathrm{C}$ ROIs ( $p=0.003$ ) of the total sample (Table 4). However, the comparison between the right and left side patellar bones shows that the right side bones present a significant difference of the mean number of NF among the A to D ROIs ( $\mathrm{p}=0.017$ ), while the left side bones don't ( $p=0.118$ ) (Tables 5 \& 6) and (Figure 3).
To achieve a more accurate distribution of the NFs on the patellar bones we have divided the patella into 20 ROIs [1-8] as shown in Figure 4. A significant difference of the mean number of NF among those 20 ROIs was observed between the right and left side bones in the 2B ( $\mathrm{p}=0.016), 3 \mathrm{C}(\mathrm{p}=0.033), 6 \mathrm{~A}(\mathrm{p}=0.024), 7 \mathrm{~A}(\mathrm{p}=0.004), 7 \mathrm{C}$ $(p=0.001)$ and $8(p=0.01)$ (Table 7)(Figure 5) and the male and female subgroups in ROI 8 ( $p=0.025$ ) (Table 8). According to the distribution of the NFs in the anterior surface of the patellar bones, 8 main different morphological types derived [1-8] (Figure 6). The percentage of appearance of each type is as follows: $1: 69 \% 2: 13 \%$, 3: $6 \%, 4: 5 \%, 5: 3 \%, 6: 2 \%, 7: \approx 1 \%, 8: \approx 1 \%$. 


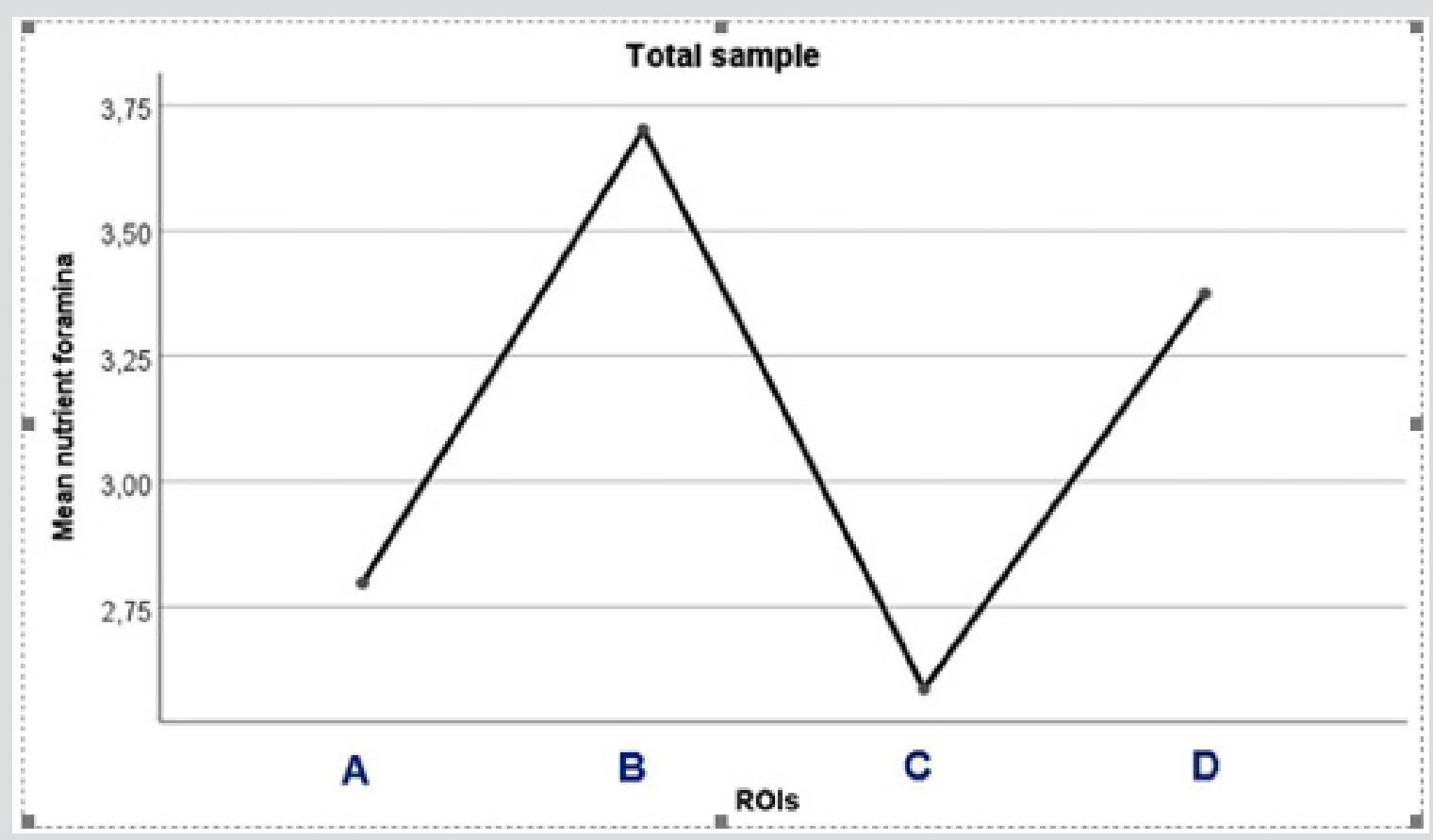

Figure 2: Distribution of NF between different areas of interest (A to D ROIs) for the total sample.

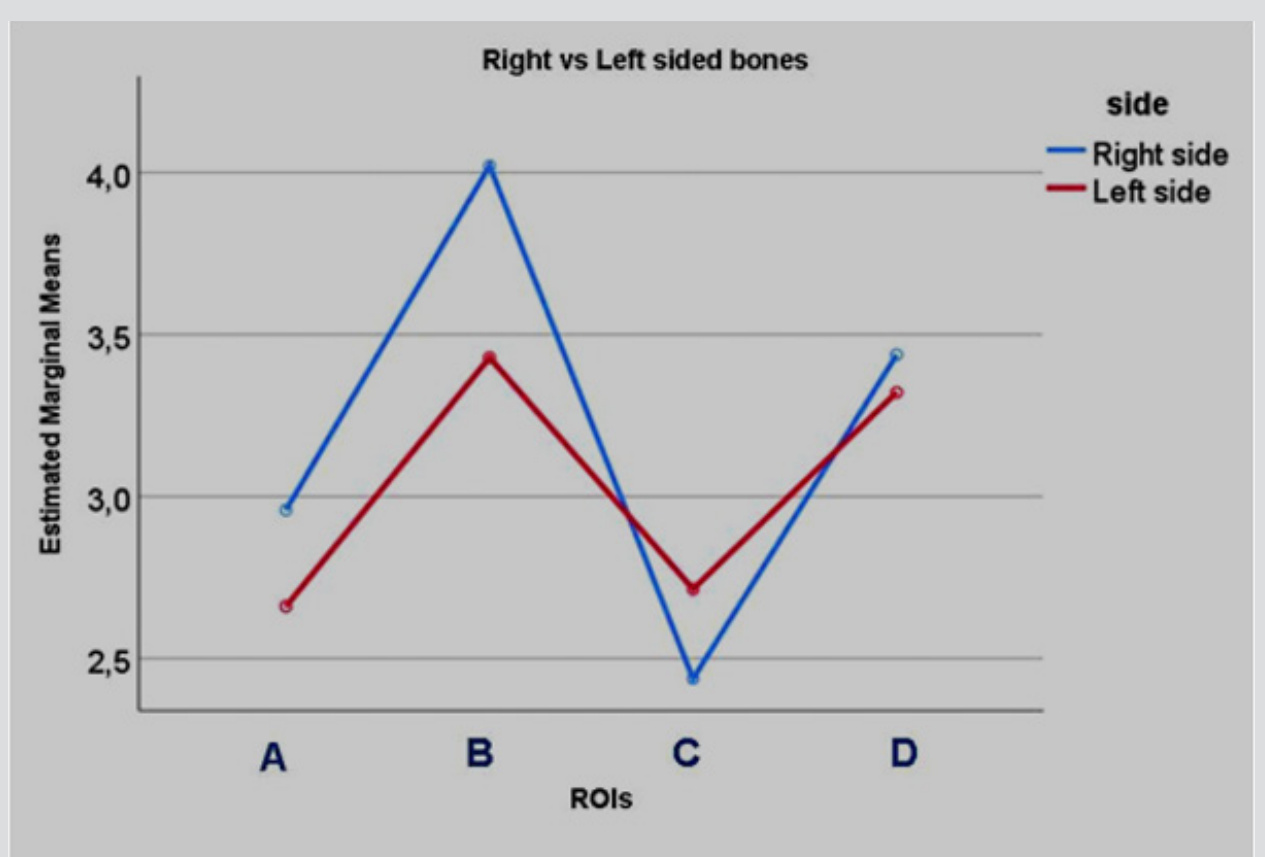

Figure 3: Distribution of NF between different areas of interest (A to D ROIs) for the right vs left sided subgroups.

Table 3: Distribution of NF between different areas of interest (A to D ROIs) for the total sample.

\begin{tabular}{|c|c|c|c|}
\hline & Mean & Std. Deviation & N \\
\hline Q1 & 2,80 & 2,317 & 104 \\
\hline Q2 & 3,70 & 2,421 & 104 \\
\hline Q4 & 2,59 & 1,641 & 104 \\
\hline
\end{tabular}

ANOVA - repeated measures $p=0.002$ 
Table 4: Differences of NF between different areas of interest (A to D ROIs) for the total sample

\begin{tabular}{|c|c|c|c|c|c|c|}
\hline \multicolumn{7}{|c|}{ Pairwise Comparisons } \\
\hline \multirow{2}{*}{$\begin{array}{l}\text { (I) factor } 1 \text { (A-D } \\
\text { ROIs) }\end{array}$} & \multirow{2}{*}{ (J) factor1 (A-D ROIs) } & \multirow{2}{*}{$\begin{array}{c}\text { Mean Difference } \\
(I-J)\end{array}$} & \multirow{2}{*}{ Std. Error } & \multirow{2}{*}{ p-value } & \multicolumn{2}{|c|}{ 95\% Confidence Interval for Difference } \\
\hline & & & & & Lower Bound & Upper Bound \\
\hline \multirow{3}{*}{ A } & B & -0.904 & 0.361 & 0.083 & -1.874 & 0.066 \\
\hline & $\mathrm{C}$ & 0.212 & 0.262 & 1 & -0.493 & 0.916 \\
\hline & $\mathrm{D}$ & -0.577 & 0.296 & 0.326 & -1.374 & 0.221 \\
\hline \multirow{3}{*}{ B } & A & -0.904 & 0.361 & 0.083 & -0.066 & 1.874 \\
\hline & $\mathrm{C}$ & $1.115^{*}$ & 0.308 & 0.003 & 0.287 & 1.944 \\
\hline & $\mathrm{D}$ & 0.327 & 0.339 & 1 & -0.584 & 1.238 \\
\hline \multirow{3}{*}{$\mathrm{C}$} & A & -0.212 & 0.262 & 1 & -0.916 & 0.493 \\
\hline & B & $-1.115^{*}$ & 0.308 & 0.003 & -1.944 & -0.287 \\
\hline & $\mathrm{D}$ & -0.788 & 0.305 & 0.067 & -1.61 & 0.033 \\
\hline \multirow{3}{*}{$\mathrm{D}$} & A & 0.577 & 0.296 & 0.326 & -0.221 & 1.374 \\
\hline & B & -0.327 & 0.339 & 1 & -1.238 & 0.584 \\
\hline & $\mathrm{C}$ & 0.788 & 0.305 & 0.067 & -0.033 & 1.61 \\
\hline \multicolumn{7}{|c|}{ Based on estimated marginal means } \\
\hline \multicolumn{7}{|c|}{ *a. The mean difference is significant at the 0.05 level } \\
\hline \multicolumn{7}{|c|}{ b. Adjustment for multiple comparisons: Bonferroni } \\
\hline
\end{tabular}

Table 5: Distribution of NF between different areas of interest (A to D ROIs) for the right-side subgroup.

\begin{tabular}{|c|c|c|c|}
\hline \multicolumn{3}{|c|}{ Descriptive Statistics $^{\text {a }}$} \\
\hline & Mean & Std. Deviation & N \\
\hline A & 2,96 & 2,729 & 48 \\
\hline B & 4,02 & 2,283 & 48 \\
\hline C & 2,44 & 1,687 & 48 \\
\hline D & 3,44 & 2,360 & 48 \\
\hline \multicolumn{2}{|c|}{ a. side = Right side } \\
\hline
\end{tabular}

Table 6: Distribution of NF between different areas of interest (A to D ROIs) for the left side subgroup.

\begin{tabular}{|c|c|c|c|}
\hline \multicolumn{3}{|c|}{ Descriptive Statisticsa } \\
\hline & Mean & Std. Deviation & N \\
\hline A & 2,66 & 1,910 & 56 \\
\hline B & 3,43 & 2,522 & 56 \\
\hline C & 2,71 & 1,604 & 56 \\
\hline D & 3,32 & 2,217 & 56 \\
\hline \multicolumn{2}{|c|}{ a. side = Left side } \\
\hline
\end{tabular}

Table 7: Differences of mean number of nutrient foramina observed between right and left sided ROIs.

\begin{tabular}{|c|c|c|c|c|c|}
\hline & \multicolumn{2}{|c|}{ Count (n) } & \multicolumn{2}{c|}{ Mean \pm SD } \\
\hline Area & Right & Left & Right & Left & p-value \\
\hline 1 & 11 & 7 & $1.36 \pm 0.67$ & $1.00 \pm 0.01$ & 0.143 \\
\hline 2A & 16 & 9 & $1.63 \pm 1.09$ & $1.43 \pm 0.50$ & 0.688 \\
\hline 2B & 34 & 17 & $2.03 \pm 0.90$ & $1.85 \pm 0.82$ & 0.016 \\
\hline 2C & 25 & 27 & $1.48 \pm 0.71$ & $1.22 \pm 0.44$ & 0.084 \\
\hline 2D & 25 & 9 & $1.60 \pm 0.96$ & $2.00 \pm 0.90$ & 0.357 \\
\hline 3A & 25 & 23 & $1.68 \pm 0.80$ & $1.73 \pm 0.70$ & 0.212 \\
\hline 3B & 30 & 26 & $1.70 \pm 0.70$ & $1.78 \pm 0.63$ & 0.033 \\
\hline 3C & 10 & 32 & $1.20 \pm 0.63$ & $2.44 \pm 1.01$ & 0.111 \\
\hline 3D & 21 & 27 & $1.95 \pm 0.80$ & $1.36 \pm 0.50$ & 0.609 \\
\hline 4 & 8 & 11 & $1.25 \pm 0.46$ & & \\
\hline
\end{tabular}




\begin{tabular}{|c|c|c|c|c|c|}
\hline 5 & 4 & 8 & $\mathrm{n} / \mathrm{a}$ & $\mathrm{n} / \mathrm{a}$ & $\mathrm{n} / \mathrm{a}$ \\
\hline $6 \mathrm{~A}$ & 40 & 21 & $2.03 \pm 0.97$ & $1.48 \pm 0.75$ & 0.024 \\
\hline $6 \mathrm{~B}$ & 16 & 7 & $1.94 \pm 0.68$ & $1.71 \pm 0.49$ & 0.465 \\
\hline $6 \mathrm{C}$ & 7 & 15 & $1.71 \pm 0.76$ & $1.67 \pm 0.72$ & 0.878 \\
\hline $6 \mathrm{D}$ & 14 & 19 & $1.64 \pm 0.84$ & $2.21 \pm 0.85$ & 0.068 \\
\hline $7 \mathrm{~A}$ & 10 & 16 & $1.10 \pm 0.32$ & $1.75 \pm 0.58$ & 0.004 \\
\hline $7 \mathrm{~B}$ & 34 & 26 & $1.65 \pm 0.77$ & $1.85 \pm 0.73$ & 0.258 \\
\hline 7C & 24 & 24 & $1.29 \pm 0.55$ & $2.21 \pm 0.66$ & 0.001 \\
\hline $7 \mathrm{D}$ & 8 & 27 & $1.75 \pm 0.89$ & $1.96 \pm 0.81$ & 0.504 \\
\hline 8 & 16 & 19 & $2.00 \pm 0.89$ & $1.32 \pm 0.58$ & 0.010 \\
\hline
\end{tabular}

Table 8: Differences of mean number of nutrient foramina observed between right and left sided ROIs.

\begin{tabular}{|c|c|c|c|c|c|}
\hline \multirow[b]{2}{*}{ Area } & \multicolumn{2}{|c|}{ Count (n) } & \multicolumn{2}{|c|}{ Mean \pm SD } & \multirow[b]{2}{*}{ p-value } \\
\hline & Males & Females & Males & Females & \\
\hline 1 & 9 & 9 & $1.44 \pm 0.73$ & 1 & $\mathrm{n} / \mathrm{a}^{*}$ \\
\hline $2 \mathrm{~A}$ & 14 & 11 & $1.36 \pm 0.50$ & $1.73 \pm 1.27$ & 0.722 \\
\hline $2 \mathrm{~B}$ & 37 & 14 & $1.70 \pm 0.91$ & $2.14 \pm 0.86$ & 0.095 \\
\hline $2 \mathrm{C}$ & 32 & 20 & $1.72 \pm 0.77$ & $1.60 \pm 0.82$ & 0.509 \\
\hline $2 \mathrm{D}$ & 19 & 15 & $1.42 \pm 0.96$ & $1.60 \pm 0.74$ & 0.186 \\
\hline $3 \mathrm{~A}$ & 28 & 20 & $1.96 \pm 1.0$ & $1.65 \pm 0.59$ & 0.359 \\
\hline $3 \mathrm{~B}$ & 29 & 27 & $1.76 \pm 0.83$ & $1.67 \pm 0.78$ & 0.680 \\
\hline $3 \mathrm{C}$ & 23 & 19 & $1.70 \pm 0.93$ & $1.58 \pm 0.84$ & 0.744 \\
\hline $3 \mathrm{D}$ & 20 & 28 & $2.20 \pm 1.01$ & $2.25 \pm 0.93$ & 0.749 \\
\hline 4 & 10 & 9 & $1.20 \pm 0.42$ & $1.44 \pm 0.53$ & 0.265 \\
\hline 5 & 4 & 8 & 1 & 1 & $\mathrm{n} / \mathrm{a}^{*}$ \\
\hline $6 \mathrm{~A}$ & 28 & 33 & $2.0 \pm 1.14$ & $1.67 \pm 0.69$ & 0.287 \\
\hline $6 \mathrm{~B}$ & 10 & 13 & $1.80 \pm 0.79$ & $1.92 \pm 0.49$ & 0.568 \\
\hline $6 \mathrm{C}$ & 11 & 11 & $1.91 \pm 0.7$ & $1.45 \pm 0.69$ & 0.114 \\
\hline $6 \mathrm{D}$ & 22 & 11 & $2.18 \pm 0.85$ & $1.55 \pm 0.82$ & 0.050 \\
\hline $7 \mathrm{~A}$ & 17 & 9 & $1.47 \pm 0.62$ & $1.56 \pm 0.53$ & 0.601 \\
\hline $7 \mathrm{~B}$ & 37 & 23 & $1.62 \pm 0.68$ & $1.91 \pm 0.85$ & 0.194 \\
\hline $7 \mathrm{C}$ & 27 & 21 & $1.74 \pm 0.76$ & $1.76 \pm 0.77$ & 0.917 \\
\hline $7 \mathrm{D}$ & 21 & 14 & $1.86 \pm 0.73$ & $2.00 \pm 0.96$ & 0.668 \\
\hline 8 & 22 & 13 & $1.86 \pm 0.89$ & $1.23 \pm 0.44$ & 0.025 \\
\hline
\end{tabular}

*. $n / a$ : small sample number

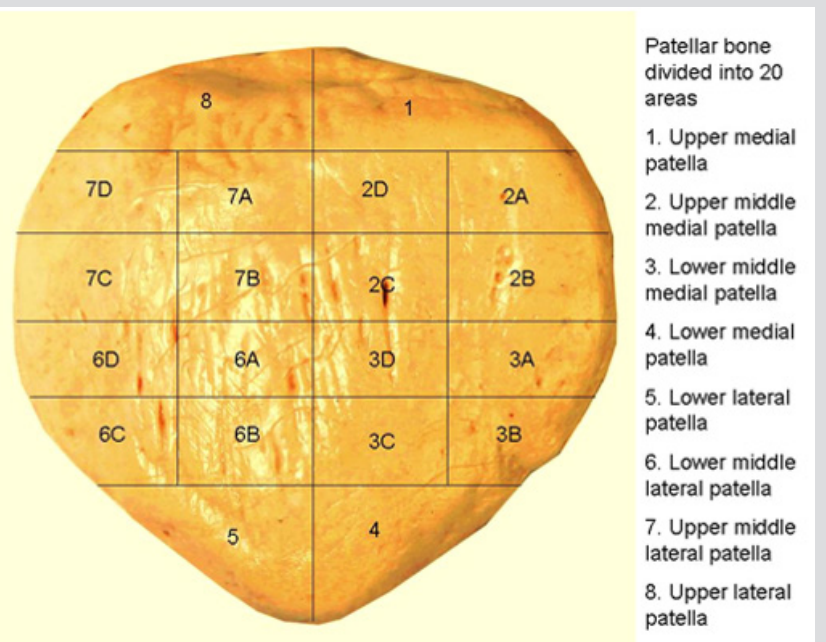

Figure 4: Patella bone divided into 20 ROIs. 


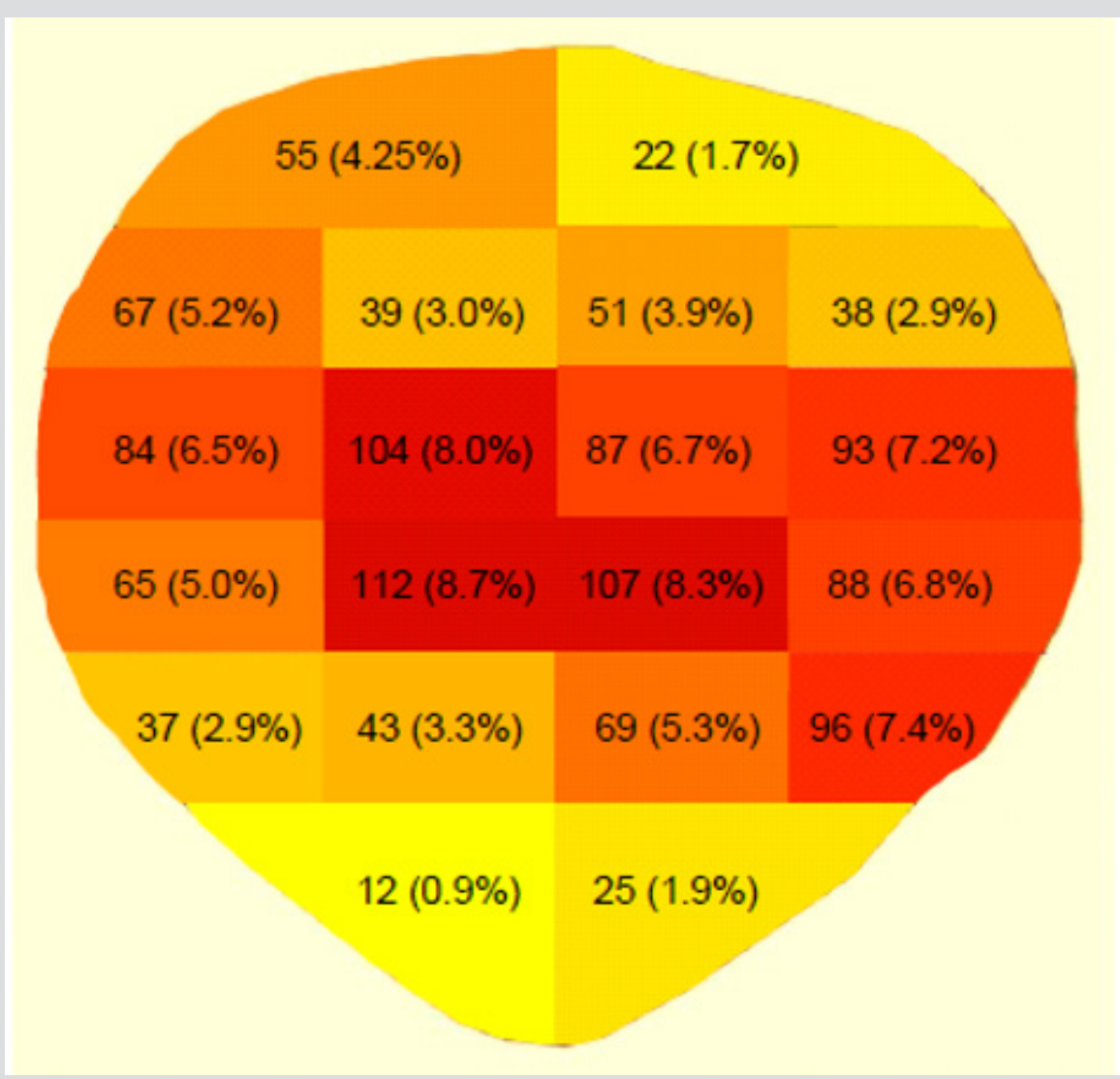

Figure 5: Patella bone divided into 20 ROIs depicting the nutrient foramina distribution and statistical significance of appearance.
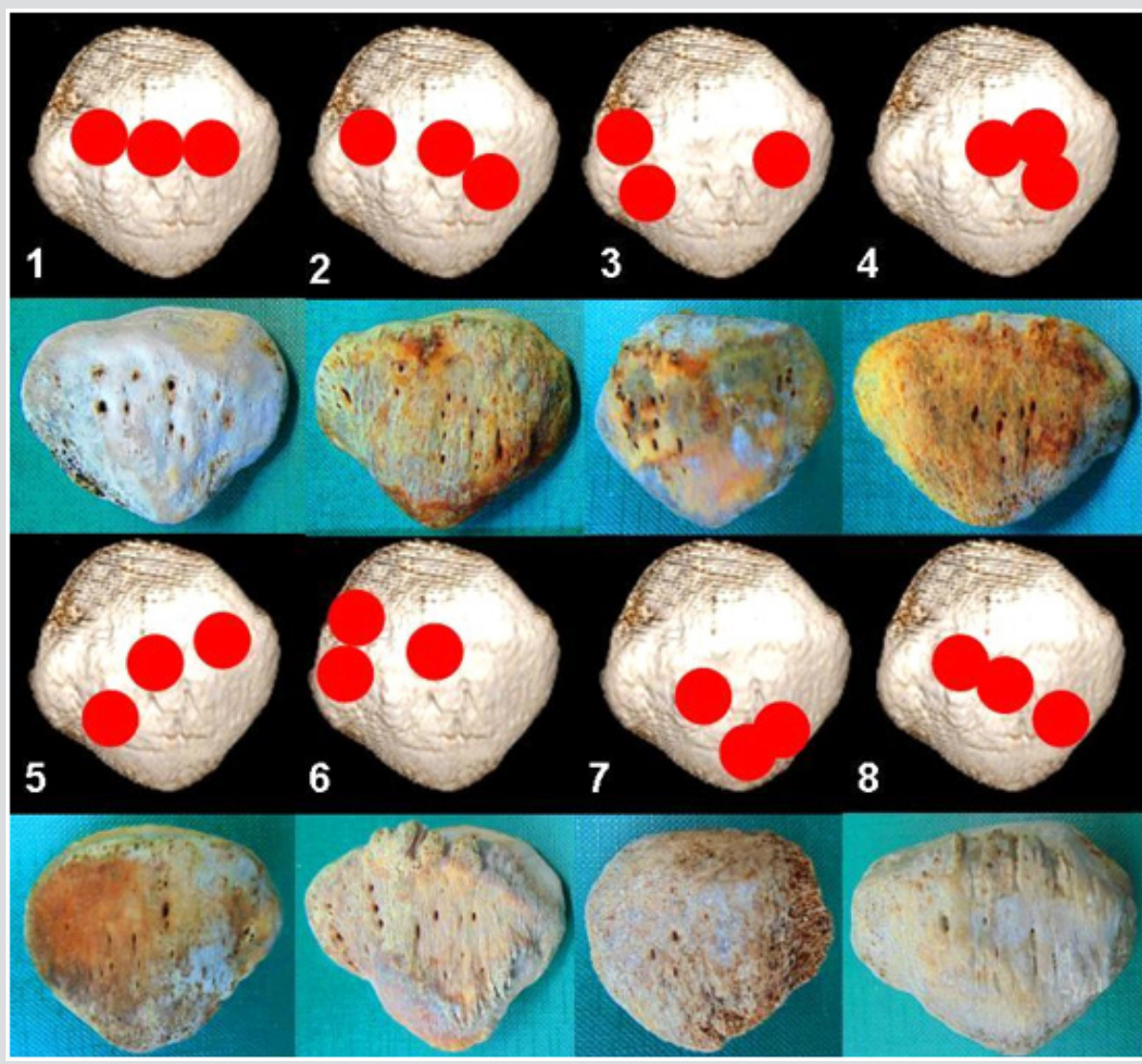

Figure 6: Cartography of the NFs, types 1-8. 


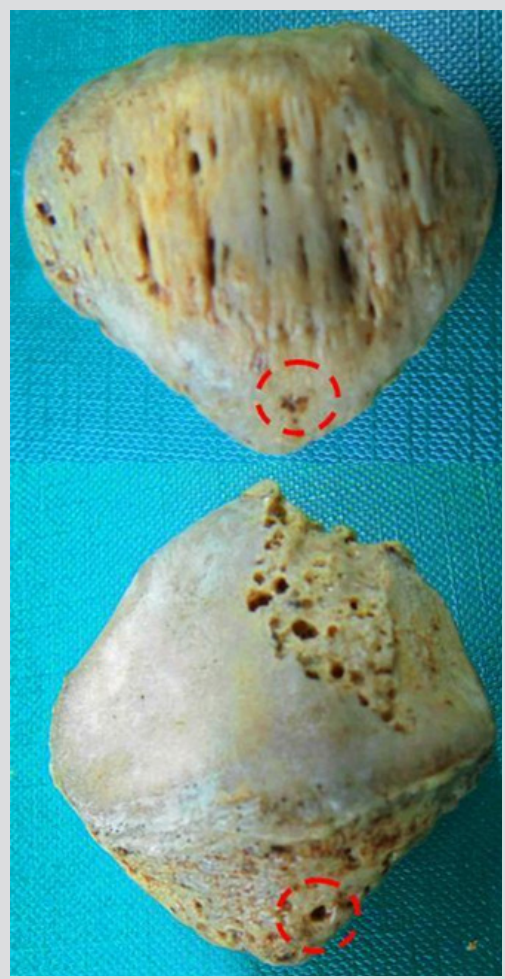

Figure 7: NFs both in the anterior and posterior surfaces of the distal third of the same patella bone.

\section{Discussion}

The subject of fractures and re-fractures (later-secondary or post-operative) of the patella has attracted many writers. Various lesions of the vascular blood supply of the patella bone may result to total knee arthroplasty, artificial patella or partial patellectomy. The "peripatellar arterial ring" is wrongfully considered as a true ring, having really an incomplete nature. Nine arteries participate to its formation, alongside with the presence of a rich extrinsic vascular plexus, that gives off nutritional patellar arteries [10]. Studies demonstrated that the dominant central arteries are branches of the lateral inferior genicular artery, while the auxiliary inferior marginal arteries derive largely from the anterior tibial recurrent vessels. Thus, they reinforce the concept of an overwhelming inferior-lateral blood path to the patella. Therefore, transverse fractures of the bone are so prone to delayed union, avascular necrosis of the proximal fragment [11-12] or a severe disturbance of the blood supply during a lateral release of the patella in total knee arthroplasty [13]. Surprisingly our dry bone sample presented high numbers of NFs in the upper part of the bone, a finding which may alter the above-mentioned concept concerning the avascular necrosis of the proximal fragment.

Even though a pattern in patella blood supply already exists, the distribution of the nutrient arteries entering the bone through its NFs in not thoroughly studied. No classification of the bone exists regarding its NFs. Several branches arise from the peripatellar arterial "ring" at the lower pole of the patella and run proximally on the anterior surface of the bone in a series of furrows, enter- ing through the NFs [9-12]. Those small vessels penetrate the bone in the middle third region $[7,14]$. However, our study demonstrated the appearance of NFs to the proximal and distal parts as well. Nonetheless, the type 1 of NFs cartography constituted the $69 \%$ of the total sample, presenting a linear NF distribution in the middle part of the bone.

There is a second blood supply network for the patella bone, arising this from the polar vessels which are branches of the infrapatellar anastomosis behind the patellar ligament. They pierce the area between the ligamentum patellae and the articular surface, running upwards, being anastomosed with the nutrient arteries of the anterior surface, supplying the distal third of the bone $[1,15]$. Our sample presented NFs both in the anterior and posterior surfaces of the distal third of the bone (Figure 7). Our study calculated a mean of almost 12.5 vascular/nutrient foramina per bone as the nutrient arteries for the patella reach it via the quadriceps tendon, while the majority of the researchers consider the number 12 as the limit $[1,7,15]$. However, others simply indicate no number, only mentioning that many NFs exist in the anterior surface [16].

In our sample, consisting of older adults of rural origin, an interrupted blood stream due to trauma or overuse (many years of hard work, continuous flexion, baring of weights etc.) may block or thrombose the main nutrient arteries running up from the middle part of the patella. This may result in increased blood flow and development of collateral genicular circulation and the presence of more than $12 \mathrm{NF}$ is some cases. We should emphasize that our sample is of dry bones, aged, probably damaged (burial attrition, time decay, osteoarthritis, osteoporosis etc.) in a specific population of the central Greece, facts which may conclude in various bias concerning our results.

\section{Conclusion}

Nutrient arteries of the anterior surface of the patella, despite of their significance in blood supply of the kneecap, are rather undervalued in recent studies concerning the area. They play an important role in the re-organisation of a broken bone, or during knee surgical interventions. Our study aimed to categorize the patella bone in agreement with the NFs cartography in a new morphology classification. Bigger sample and further research are needed to connect blood supply with clinical anatomy of the knee joint.

\section{References}

1. Scuderi GR (1995) The patella, Springer Verlag New York, USA.

2. Flandry F, Hommel G (2011) Normal Anatomy and Biomechanics of the Knee. Sports Med Arthrosc Rev 19: 82-92.

3. Cunningham C, Scheuer L, Black S (2016) Developmental Juvenile Osteology. Academic Press-Elsevier, London.

4. Blackburn JS, Peel TE (1977) A new method of measuring patellar height. Journal of Bone and Joint Surgery 59(2): 241-242.

5. Corner EM (1900) Structure, Fracture, and Refracture of the Patella. Ann Surg 32(6): 749-768.

6. Kaufer H (1971) Mechanical function of the patella. Journal of bone and Joint Surgery 53(8): 1551-1560. 
7. Scapinelli R (1967) Blood supply of the human patella. Its relation to ischaemic necrosis after fracture. J Bone Joint Surg Br 49(3): 563-570.

8. Melvin JS, Mehta S (2011) Patellar fractures in adults. J Am Acad Orthop Surg 19(4): 198-207.

9. Boström A (1972) Fracture of the patella. A study of 422 patellar fractures. Acta Orthop Scand Suppl 143: 1-80.

10. Catalano JB, Iannacone WM, Marczyk S, Dalsey RM, et al. (1995) Open fractures of the patella: long-term functional outcome. J Trauma 39(3): 439-444.

11. Scapinelli R (1967) Blood supply of the human patella. J Bone Joint Surg [Br] 49(3): 563-570.

\section{ISSN: 2574-1241}

DOI: 10.26717/BJSTR.2019.17.003051

Gregory Tsoucalas. Biomed J Sci \& Tech Res

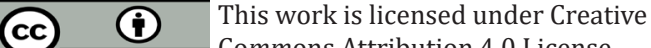

Submission Link: https://biomedres.us/submit-manuscript.php
12. Arlet J, Mazieres B (1990) Bone circulation and bone necrosis. Springer Verlag, Berlin.

13. DeBella H, Pintera Z, Pintoa M, Bergstressera S, Leea S, et al. (2019) Vascular supply at risk during lateral release of the patella during total knee arthroplasty: A cadaveric study. Journal of Clinical Orthopaedics and Trauma 10(1): 107-110.

14. Scott NW (2011) Insall \& Scott Surgery of the Knee. Elsevier Health Sciences, Philadelphia.

15. Trueta J (2014) Studies of the Development and Decay of the Human Frame. Butterworth-Heinemann, London.

16. Draves DJ (1986) Anatomy of the Lower Extremity. Williams \& Wilkins, Bltimore.

$\begin{array}{ll}\text { BIOMEDICAL } & \text { Assets of Publishing with us } \\ \text { RESEARCHES } & \text { - Global archiving of articles } \\ \text { - Immediate, unrestricted online access } & \text { - Rigorous Peer Review Process } \\ & \text { - Authors Retain Copyrights } \\ \end{array}$

